\title{
Urbanització difusa i consum d'aigua per a usos domèstics. Una exploració de relacions
}

\author{
Xavier Garcia \\ Universitat de Girona. Departament de Geografia \\ xavier.garciaacosta@udg.edu
}

Recepció: juliol de 2012

Acceptació: octubre de 2012

\section{Resum}

A l'àmbit mediterrani, amb problemes recurrents de disponibilitat hídrica, l'ús de l'aigua destinada als usos exteriors dels habitatges unifamiliars, aïllats o adossats (piscina, jardí, hort, etc.), esdevé un dels factors importants a l'hora d'entendre per què aquest model residencial computa uns consums d'aigua per càpita superiors en comparació als models residencials d'alta densitat. Tot i així, unes altres característiques del model urbà i dels seus habitatges poden esdevenir determinants a l'hora d'entendre i d'estimar el metabolisme hídric d'aquests espais urbans residencials. Aquest article tracta d'esclarir quina és la interrelació existent entre els processos d'urbanització i els patrons socials en el consum d'aigua per a usos domèstics, en especial en àmbits urbans de baixa densitat. Ho fa centrant l'atenció en la pràctica de la jardineria i els diferents usos de l'aigua a l'exterior dels habitatges.

Paraules clau: gestió de l'aigua; urbanització; habitatge unifamiliar; usos domèstics de l'aigua; jardí.

Resumen. Urbanización difusa y consumo de agua para usos domésticos. Una exploración de relaciones

En el ámbito mediterráneo, con problemas recurrentes de disponibilidad hídrica, el uso del agua destinada a los usos exteriores de las viviendas unifamiliares, aisladas o adosadas (piscina, jardín, huerto, etc.), resulta uno de los factores importantes para entender por qué este modelo residencial computa unos consumos de agua por cápita superiores comparados con los modelos residenciales de alta densidad. Sin embargo, otras características del modelo urbano y de sus viviendas pueden resultar determinantes para entender y estimar el metabolismo hídrico de estos espacios urbanos residenciales. Este artículo trata de esclarecer cuál es la interrelación existente entre los procesos de urbanización y los patrones sociales en el consumo de agua para usos domésticos, en especial en ámbitos urbanos de baja densidad. Lo hace centrando la atención en la práctica de la jardinería y los diferentes usos del agua en el exterior de las viviendas.

Palabras clave: gestión del agua; urbanización; vivienda unifamiliar; usos domésticos del agua; jardín. 
Résumé. Urbanisation diffuse et usages domestiques de l'eau. Exploration de relations

Dans la région méditerranéenne, avec des problèmes récurrents de disponibilité hydrique, l'usage domestique de l'eau à l'extérieur des maisons isolées ou jumelées (piscine, jardin, verger, etc.), est un facteur important lorsque comprendre pourquoi ce modèle a besoin d'une consommation d'eau résidentielle par habitant plus élevé en comparaison à des modèles de haute densité résidentielle. Toutefois, d'autres caractéristiques du modèle urbain et de leurs maisons peuvent devenir décisives pour la compréhension et l'estimation du métabolisme de l'eau dans ces zones urbaines résidentielles. Cet article vise à clarifier ce qui est la relation entre les processus d'urbanisation et des structures sociales de la consommation domestique d'eau, en particulier dans les modèles d'urbanisation diffuse, particulièrement sur la pratique du jardinage et les différents usages de l'eau en dehors de la maison.

Mots clé: gestion de l'eau; urbanisation; maisons isolées; jardin; usages domestiques de l'eau.

\section{Abstract. Urban sprawl and domestic water consumption: An exploration of relations}

In the Mediterranean, which suffers from persistent problems of water availability, the outdoor water uses of detached and semi-detached dwellings (swimming pools, gardens, orchards, etc.) are an important factor to understand why this residential model is associated with higher water consumption per capita than high-density residential areas. However, other features of the urban model and its dwellings might turn out to be decisive for understanding and estimating the water metabolism of these urban residential areas. This paper seeks to clarify the interrelationship between these urban processes and social patterns of domestic water consumption, especially in low-density urban areas, while focusing on gardening practices and different outdoor water uses.

Keywords: water management; urbanization; detached housing; domestic water uses; garden.

\section{Sumari}
1. Introducció
4. El consum d'aigua al jardí
2. Model d'urbanització difusa
5. Conclusions
i consum d'aigua
Referències bibliogràfiques
3. Característiques de l'habitatge i consum d'aigua

\section{Introducció}

La creixent preocupació sobre la disponibilitat d'aigua en quantitats i qualitats suficients ha convertit en urgent la necessitat d'avançar cap a un enfocament de sostenibilitat en la planificació i la gestió dels recursos hídrics. En aquest sentit, moltes organitzacions internacionals, incloses les Nacions Unides $\mathrm{i}$ la Unió Europea (Nacions Unides, 2006; European Environment Agency, 2009), proposen l'aplicació d'un model de gestió integrat que combini accions pel que es refereix a l'oferta d'aigua, però, molt especialment, pel que es refe- 
reix a la demanda. L'enfocament orientat en la demanda parteix del control del consum en un intent seriós de fer-lo correspondre amb els recursos hídrics disponibles, és a dir, amb l'oferta. Els recursos hídrics de cada país han de ser protegits, conservats, gestionats, utilitzats i controlats, de manera que s'asseguri l'ús eficient, sostenible i beneficiós de l'aigua com a bé d'interès públic (Bakir, 2001).

Per tal de portar a terme polítiques de planificació i gestió sostenible del recurs en el context dels usos residencials, es requereix un coneixement el màxim d'exhaustiu possible de la naturalesa i de les característiques d'aquesta demanda, com també de les dimensions territorials i temporals que presenta. Els canvis en l'estil de vida esdevenen un dels vectors més importants per entendre per què ha augmentat la demanda d'aigua, sobretot en l'àmbit dels usos domèstics. Entre aquests canvis en l'estil de vida, cal destacar l'increment de l'interès de la població per residir en habitatges unifamiliars. Així, el sorgiment del nou model residencial difús ha fet possible l'aparició de pautes noves de comportament que porten implícit el consum d'aigua amb finalitats recreatives, com ara les piscines o els jardins.

L'expansió de la urbanització difusa s'ha desenvolupat de forma completament aliena a les repercussions que implica aquest model en la demanda d'aigua de la xarxa d'abastament (European Environment Agency, 2006). La pròpia estructura de la urbanització difusa, per la simple circumstància que la seva xarxa de distribució d'aigua sol ésser més gran i ramificada, fa més costós el manteniment de la xarxa de subministrament i és més propensa a patir fuites (Yepes i Dianderas, 1996). També aquest model de ciutat jardí s'alinea amb el model de benestar individual i transmet uns valors socials que poden portar cap a conductes poc responsables envers el recurs hídric. Esdevenen, en el pitjor dels casos, autèntics paisatges urbans on els jardins es converteixen en els escenaris on es dóna un «hidrofetitxisme» encaminat a assolir una distinció social o com a via per mostrar que es compleix amb les normes socials establertes entre els residents de la comunitat suburbana (Askew i McGuirk, 2004).

L'objectiu d'aquesta contribució és presentar, des d'un enfocament pluridisciplinari, la interrelació existent entre els processos d'urbanització i els patrons socials de consum d'aigua per a usos domèstics, en especial en àmbits urbans de baixa densitat, i centrant l'atenció en la pràctica de la jardineria i els usos de l'aigua que hi estan associats.

Primerament, l'article exposa les diferents característiques que expliquen la relació entre el model d'urbanització difusa i el consum d'aigua per a usos domèstics. En segon lloc, l'estudi es proposa discernir com diferents característiques de l'habitatge poden intervenir a l'hora de determinar el consum domèstic d'aigua d'una llar. A continuació, i dins de l'àmbit de l'habitatge, l'estudi centra l'atenció en l'element jardí i els factors que determinen disposar d'un jardí menys eficient en termes hídrics. S'hi explora també la rellevància que prenen els sistemes de reg i les fonts de proveïment utilitzats a l'hora d'explicar com de consumptiu pot ésser un jardí. Finalment, es dedica un darrer apartat a recollir les conclusions principals extretes de l'estudi. 


\section{Model d'urbanització difusa i consum d'aigua}

Les característiques que descriuen els models urbans dels nostres pobles i ciutats poden esdevenir determinants per entendre els requeriments hídrics dels seus habitants a les llars respectives. Malauradament, sorprèn la poca atenció que s'ha prestat en la manera com el consum d'aigua per a usos domèstics varia a través d'àrees urbanes de característiques diferents i com aquest fet pot ésser utilitzat a l'hora de plantejar estils nous de planificació i gestió del territori (Troy i Holloway, 2004). No obstant això, se sap que la previsió de les provisions fiables d'aigua potable ha determinat durant molt de temps el desenvolupament urbanístic en països on aquest recurs no és abundant. La tipologia d'habitatge predominant i el model urbà del qual forma part poden generar diferents patrons de consum d'aigua a les llars. Generalment, s'admet que les formes urbanes compactes són més eficients en l'ús dels recursos naturals i, per tant, més sostenibles que les formes disperses (Rueda, 1995).

Pel que fa exclusivament a la tipologia d'habitatge, l'impacte principal de l'expansió de l'habitatge unifamiliar (el qual sol presentar un espai exterior privat) respecte a l'ús i el consum d'aigua és que possibilita l'aparició d'usos exteriors a la llar amb fins recreatius, com ara les piscines, els jardins, les banyeres d'hidromassatge o, simplement, l'horticultura (Saurí, 2003). Per fer-se una idea de fins a quin punt els consums exteriors poden ser importants, a Austràlia, es comptabilitzà que el 44\% de l'aigua consumida a les llars l'any 2001 es dedicava a usos exteriors (Australian Bureau of Statistics, 2004). També Mayer et al. (1999), en el seu estudi aplicat a dotze ciutats dels EUA, van calcular que, de mitjana, les llars enquestades gastaven un 58\% del total de l'aigua en usos exteriors. Segons aquests autors, el determinant més important del consum a l'exterior de la llar era la presència de piscina. Els habitatges amb piscines utilitzaven dues vegades més aigua a l'exterior que els que no en tenien. Altres autors, en el cas dels estats de Nova York i California, defensen que el reg del jardí és l'ús de l'aigua a l'exterior més consumptiu i que el sistema amb el qual es rega la gespa pot representar una proporció molt significativa de la variància en els valors dels consums exteriors (Chestnutt i Mcspadden, 1991; Renwick i Archibald, 1998). Fox et al. (2009), en l'estudi que van realitzar a Stevenage (Regne Unit), a partir de dades de consum diari d'aigua per a usos domèstics de 1.555 llars, van trobar que aquelles que posseïen jardí consumien, de mitjana, 152 litres més d'aigua per llar i dia a l'estiu que aquelles que no en posseïen i 124 litres més per llar i dia durant els mesos d'hivern. Però cal remarcar, també, que aquelles llars sense jardí també solien tenir menys habitacions i, per tant, menys residents en cadascuna.

Tot $\mathrm{i}$ això, cal esmentar que certes característiques d'aquestes àrees urbanes poden matisar la premissa que la ciutat compacta, i el model residencial respectiu de densitat elevada, és més eficient en l'ús dels recursos hídrics. Per exemple, el nombre de persones que habiten a la llar sol ésser significativament superior a les urbanitzacions de baixa densitat (Loh i Coghlan, 2003; Domene i Saurí, 2006). A causa de les economies d'escala que es creen en els usos de l'aigua dels 
habitatges, l'increment de la demanda d'aigua és proporcionalment inferior a l'increment de la mida de les cases (Höglund, 1999), per tant, els consums per càpita d'una llar amb més membres sol comportar un ús més eficient de l'aigua en aquesta llar.

La ciutat compacta també ha estat assenyalada com a generadora del fenomen conegut amb el nom de multiresidència (possessió d'un habitatge secundari o més) (Gössling, 2002), cosa que genera que els usuaris de l'aigua localitzin la seva demanda en altres espais, tal com s'especifica a l'apartat següent. Per tant, el rebuig de qualsevol tipus de suburbanització com a alternativa vàlida de planificació influeix en l'elevada propensió de les llars de la ciutat compacta a disposar d'un habitatge secundari (Módenes i Colás, 2005). Estudis com els de Colom i Molés (1999) i Módenes i Colás (2005) pel que respecta al cas espanyol demostren que la mida del municipi o fins i tot el nombre d'habitatges per edifici són variables positivament relacionades amb la probabilitat de tinença, per part dels habitants d'aquestes llars, d'una segona residència, amb la condició socioeconòmica com a factor molt important també que cal tenir en compte. A més a més, sol coincidir que el turisme es concentra en àrees que, a priori, disposen de menys aigua, com ara les zones costaneres, la qual cosa accelera els problemes preexistents (Gössling, 2002).

En termes de sostenibilitat ambiental, Troy (2005) justifica que, en el cas d'Austràlia, les formes residencials unifamiliars aïllades podrien ser la clau perquè les futures ciutats poguessin assolir una reducció de l'estrès ambiental. La seva capacitat d'adaptació i flexibilitat els atorga més capacitat per adaptarse als nous enfocaments de prestació dels serveis urbans, citant per exemple el subministrament d'aigua, des del moment que l'estructura de la ciutat difusa representa una oportunitat per a la generació de fonts renovables d'energia o subministrament d'aigua descentralitzats.

\section{Característiques de l'habitatge i consum d'aigua}

Diferents autors han introduit, en els seus models de demanda d'aigua per a usos domèstics, unes altres característiques de l'habitatge, com ara el nombre d'habitacions (Barkatullah, 1996; Dandy et al., 1997), la quantitat de cambres de bany (Chicoine i Ramamurthy, 1986; Barkatullah, 1996) o la mida de la parcel.la (Dandy et al., 1997; Pint, 1999; Troy i Holloway, 2004). Altres, com ara Domene i Saurí (2006), Rico-Amorós et al. (2009) i Fox et al. (2009), van incloure la tipologia de l'habitatge com a variable categòrica en els seus estudis respectius, en lloc d'utilitzar variables que descrivissin les característiques de la llar on resideix l'usuari. Domene i Saurí (2006) també van confirmar com la tipologia d'habitatge (habitatges plurifamiliars, plurifamiliars amb jardí i piscina comunitària o habitatge unifamiliar) era un dels factors més importants a l'hora d'explicar els consums d'aigua en una mostra de llars de la Regió Metropolitana de Barcelona.

L'edat de l'habitatge també és un factor determinant en els consums d'aigua per a usos domèstics. Les llars de construcció recent són menys susceptibles 
de patir fuites, tant dins de la mateixa propietat com en el conjunt de la xarxa pública d'abastament. És per aquest motiu que s'espera que el consum per càpita sigui més baix en els habitatges nous que no pas en aquells més antics (Nauges i Thomas, 2000). Contràriament, Nieswiadomy i Molina (1989) van trobar, en l'estudi que van realitzar sobre la ciutat de Denton (Texas), que l'edat de l'habitatge era una variable que es relacionava negativament amb els consums d'aigua. Els autors justifiquen el resultat argumentant que els habitatges nous solen tenir més aparells que utilitzen aigua (com ara els rentavaixelles) i uns arbres amb el dosser menys desenvolupat que no minimitzen l'evapotranspiració de la gespa del jardí.

El model de tinença de l'habitatge (de lloguer o propietat) també és una variable que pot comportar patrons diferents en el consum d'aigua per a usos domèstics. La compra de la llar és la inversió principal que la majoria de les famílies realitza al llarg de la seva vida; per exemple: en el cas de l'economia espanyola, l'habitatge representa el $80 \%$ de la renda familiar (Molés i Colom, 2006). La construcció d'una piscina o d'un jardí es podria valorar més com una inversió que no pas com un cost innecessari, tot i que fa augmentar el consum d'aigua (Syme et al., 1990-1991). Gardener i Stern (1996) expliquen que, tot i que els canvis en els valors ambientals de les persones poden tenir efecte sobre la seva voluntat de dur a terme accions a favor del medi, la presència de barreres o "condicions estructurals» en el nostre entorn social pot limitar severament les accions que els individus poden emprendre. Un exemple clar d'aquesta idea és la dificultat per fer viable el transport públic (acció a favor del medi) en espais urbans de baixa densitat (condició estructural). Que l'habitatge sigui de lloguer és uns dels motius que citen aquests autors com a limitador per portar a terme accions que afavoreixin l'estalvi de l'aigua, ja que, sovint, en aquests casos, la compra d'electrodomèstics més eficients o la reparació de fuites és a càrrec del propietari. No obstant això, hi ha hagut uns altres estudis que han posat en qüestió aquesta idea. Per exemple, Clarke et al. (1997), en el seu estudi portat a terme a Leeds (Regne Unit), van trobar que els residents propietaris presentaven un consum d'aigua per llar superior al de les llars que ocupaven un habitatge de lloguer. Afegint més incògnites a aquesta constatació, Nieswiadomy i Cobb (1993), en l'estudi que van realitzar a diferents estats dels EUA, van incloure, en les seves funcions de la demanda, la variable del percentatge de llars de propietat, i van mostrar que aquesta no influïa de manera significativa sobre el consum final d'aigua.

D'altra banda, també és rellevant considerar el model d'ocupació de les llars. Determinar la proporció d'habitatges que s'utilitzen només una part de l'any (el que s'entén com a segona residència), de les que són residències principals podria ajudar a identificar aquelles comunitats on l'ús estacional de l'aigua pot tenir un impacte considerable (Arbués et al., 2003). Martínez-Espiñeira (2002), en l'estudi realitzat a partir de dades agregades pels municipis del nordoest de l'Estat espanyol, va utilitzar i demostrar la significació d'una variable que descrivia quina proporció dels habitatges dels municipis eren primeres residències. Un efecte similar va ésser trobat per Arbués et al. (2008) en l'estudi 
que van realitzar sobre la ciutat de Saragossa. En el seu model de demanda d'aigua per a diferents mides de la llar, van utilitzar una variable climàtica dicotòmica que prenia el valor 1 si la mitjana de les temperatures màximes del període de lectura superava els $18^{\circ} \mathrm{C}$ i 0 en el cas oposat. Contràriament al que s'esperava, aquesta variable va presentar un coeficient negatiu. Els autors justifiquen aquest efecte per la tendència de les famílies a marxar fora de la ciutat quan la calor s'intensifica, fet que provoca la disminució del consum d'aigua a les llars.

De forma similar, Troy i Holloway (2004) van detectar que els habitatges de densitat mitjana del centre de la ciutat d'Adelaide (Austràlia) consumien significativament menys aigua per llar en comparació al mateix tipus d'habitatge ubicat en altres districtes de la ciutat. Els autors ho expliquen a causa del fet que un gran nombre de residents en habitatges de densitat mitjana del centre de la ciutat passen una proporció significativa de l'any fora de casa seva, per exemple: en habitatges ubicats a la costa o a la muntanya. Per tant, tot i que la tipologia de llar era similar en tots els casos, els consums per càpita que es registraven als afores eren superiors als de les llars del centre de la ciutat. En conseqüència, els moviments estacionals de residents, tant en un lloc turístic receptor on es localitza un nombre abundant de segones residències, com en centres de ciutats o altres espais urbans, els residents dels quals passen un cert temps fora de l'habitatge principal, són fenòmens que poden influenciar de manera significativa en els consums d'aigua per a usos domèstics en tots dos espais urbans, la qual cosa desequilibra la balança dels consums per càpita.

\section{El consum d'aigua al jardí}

Els usos exteriors dels habitatges, com ara el reg del jardí, poden arribar a representar el 50\% del volum d'aigua provinent de la xarxa que es consumeix en una llar. A més a més, el reg del jardí, igual que omplir la piscina, es considera un ús de l'aigua discrecional. És per aquest motiu que les administracions situen en el punt de mira aquest tipus d'usos a l'hora de realitzar restriccions del consum en èpoques de sequera. N'és un exemple, per al cas de Catalunya, el Decret 84/2007 de sequera, on, a l'article 12.4, es preveu la prohibició de destinar aigua apta per al consum humà per a la pràctica d'usos com ara el reg de jardins quan s'activi l'escenari d'excepcionalitat de nivell 2. Tals fets motiven que, en els darrers anys, diversos autors hagin centrat la seva recerca en els factors que determinen el tipus d'enjardinament que s'acaba adoptant com a mitjà de gestió per assolir més eficiència en els consums d'aigua (Larsen i Harlan, 2006; Mustafa et al., 2010; Hurd, 2006; Yabiku, et al., 2008).

Diferents raons poden motivar els residents d'una llar a tenir un jardí a la part exterior del seu habitatge. Una casa amb jardí pot comportar, per exemple, l'augment tant del valor de venda de la casa (Syme et al., 1980), com del sentit de pertinença a un lloc (Sime, 1993). També, cada vegada més, s’ha convertit en un espai per a la recreació, pot desenvolupar una important funció quant a les relacions d'un mateix amb la família i les amistats (Bhatti i Church, 2000) 
i pot esdevenir un element clau en termes de tendència actual de presentació social, sobretot a través de les seves parts més visibles (Larsen i Harlan, 2006). El jardí pot arribar a representar, fins i tot, una via per desenvolupar experiències sensorials de contacte amb la natura o un lloc per evadir-se de les preocupacions personals quotidianes (Bhatti i Andrew, 2004).

Tres són els factors principals que determinen el volum d'aigua que es consumeix en un jardí: la tipologia d'enjardinament escollit, el seu sistema de reg i la font d'aigua utilitzada per regar.

\subsection{Tipus de jardí}

Hurd (2006), en un estudi realitzat a tres ciutats de l'estat de Nou Mèxic (EUA), va demostrar que la superfície del jardí que s'ocupava amb gespa estava directament relacionada amb el preu de l'aigua, el nivell d'educació i el grau de conscienciació dels residents en relació amb l'estalvi hídric. Com més elevat era el preu de l'aigua, més petit era el percentatge de gespa al jardí i més gran la superfície ocupada pels elements que no necessitaven reg o que eren molt resistents a l'escassetat hídrica.

La situació socioeconòmica de les llars també influencia el tipus de jardí elegit (Larson et al., 2009). Puix que el jardí privat pot ésser vist com un element residencial orientat a comunicar tant el poder adquisitiu que ostenten els veïns com la identitat que tenen dins la comunitat (Larsen i Harlan, 2006), els ingressos són determinants en les preferències. En el cas de la Regió Metropolitana de Barcelona, per exemple, la gespa és l'element vegetal més important en superfície en els jardins privats de les llars amb ingressos més elevats. En canvi, en el cas de famílies de classe mitjana, l'arbust mediterrani és el que adquireix preferentment aquest rol (Domene i Saurí, 2003).

Larsen i Harlan (2006), en l'estudi portat a terme a Phoenix (EUA), van demostrar que, a la part del jardí que dóna al davant de l'habitatge, els propietaris amb ingressos baixos tendeixen a preferir-hi el jardí de gespa, mentre que els propietaris de rendes mitjanes hi prefereixen el jardí de vegetació nativa i els d'ingressos més elevats opten pel jardí de vegetació nativa o del tipus «oasi» (es caracteritza perquè té vegetació exuberant i la majoria de les plantes que hi ha són espècies exòtiques que recreen un ambient tropical i que requereixen ésser regades assíduament). Els mateixos autors també demostren que les limitacions econòmiques suposen una barrera per als propietaris perquè les preferències envers el tipus de jardí coincideixin amb el que tenen en realitat. Hope et al. (2003) van trobar, en el cas de l'àrea metropolitana de Phoenix (EUA), una clara relació entre el nivell de riquesa del sector on s'ubica la llar i la diversitat de vegetació que es troba al jardí, de tal manera que l'augment dels ingressos de les famílies porta a paisatges urbans amb una diversitat més gran de plantes. Aquest fenomen s'ha arribat a batejar amb el nom d'«efecte de luxe» (en anglès: luxury effect). Un altre estudi realitzat per Mustafa et al. (2010), a Sant Petersburg (Florida), va aportar resultats contradictoris. Aquest autor va mostrar que l'aplicació de jardins més xèrics (extrem oposat a la gespa) no sembla 
que augmenti de manera uniforme amb els ingressos de les llars. Van trobar evidències que suggereixen que la tendència a la xerojardineria s'incrementa amb el nivell educatiu, indiferentment del nivell socioeconòmic. Hurd (2006) va mostrar resultats similars, ja que va trobar que el nivell educatiu moderava el desig de plantar gespa i que contribuïa decisivament a triar jardins amb pocs requeriments hídrics.

La disposició espacial dels habitatges també té un paper rellevant en la determinació dels patrons d'enjardinament. Aquest efecte seria més important a la part més visible del jardí, el davant, més orientat a seguir els estàndards de conformitat social, en contrast amb el pati del darrere, més orientat a l'oci i al temps lliure (Larsen i Harlan, 2006). Així ho constaten Zmyslony i Gagnon (2000) en el seu estudi realitzat a Montreal (Canadà), a escala de secció del carrer. Els autors trobaren que la distància (proximitat) i la similitud de cada llar en relació amb la del costat $\mathrm{i}$ altres paràmetres físics augmenten la similitud dels jardins davanters de la secció de cada carrer.

En un estudi realitzat als jardins privats de la ciutat de Mesa (Arizona), Yabiku et al. (2008) van demostrar que un dels factors que determinen la preferència pel jardí xèric era el gènere, de manera que és el gènere femení el que menys valora l'opció xèrica. Larson et al. (2009), referint-se a aquest mateix resultat, argumenten, en primer lloc, que els pares amb fills podrien percebre els jardins xèrics com potencialment més perillosos (llits de roques, espècies amb punxes, etc.). Si addicionalment es té en compte, tal com constaten Davidson i Freudenburg (1996), que les dones són generalment més propenses a preocupar-se pels perills que amenacen les seves famílies que els homes, els darrers arguments donen suport al resultat obtingut per Yabiku et al. (2008). No obstant això, uns altres estudis, com el de Hurd (2006), no sempre han trobat una relació significativa entre la presència de nens i jardins amb molta gespa.

Head et al. (2004) van estudiar com els antecedents culturals dels diferents grups ètnics que van emigrar a Austràlia condicionaven el tipus de jardineria que es practicava a la llar. Als patis dels residents procedents de la Macedònia i el Vietnam, hi abundava la producció d'hortalisses i arbres i arbusts fruiters. Els jardins dels originaris d'Anglaterra eren més variats: mentre alguns preferien plantar-hi flors ornamentals no natives, els altres es decantaven per les plantes natives.

L'edat de l'habitatge es va incloure com a variable explicativa a l'estudi portat a terme a Phoenix (EUA) per Larsen i Harlan (2006). La seva hipòtesi de partida era que el llegat dels promotors urbanístics (utilitzant l'edat de la casa com a indicador) és una de les variables més rellevants que determinen el tipus de jardí predominant a la part del davant de l'habitatge, però no és així en el cas del jardí del darrere. En realitat, els seus resultats indiquen que la probabilitat que un promotor hagi posat un jardí tipus gespa o oasi (en lloc de plantes natives) al pati del davant d'un habitatge de nova construcció ha disminuït en els últims anys.

Juntament amb la conformitat social i els factors espacials que influeixen en els patrons d'enjardinament, unes altres variables de tipus cultural o psi- 
cològic poden contribuir a explicar quin tipus de jardineria es prefereix o es practica en una llar. Així, en un altre estudi portat a terme a la ciutat de Las Cruces (EUA), es va comprovar que els residents que albergaven més coneixement sobre les plantes del jardí mostraven més preferència per la presència de plantes no autòctones al seu jardí (St. Hilaire et al., 2003). Yabiku et al. (2008) van fer hipòtesis sobre la circumstància que la "socialització» (entesa com els anys viscuts a la ciutat de Phoenix) té efectes clars sobre les preferències d'enjardinament. Es podria esperar que els processos de socialització fessin que els individus nascuts en ambients àrids apreciessin, en gran manera, els jardins xèrics amb poques necessitats hídriques. No obstant això, els resultats van mostrar un comportament, ja que, com més temps feia que els individus vivien a Phoenix, menys es preferia enjardinar amb plantes natives o de requeriments hídrics baixos. Aquests resultats no es contradiuen amb les investigacions prèvies realitzades en un context similar, com és el cas de la ciutat de Las Cruces (USA), on es demostra que els natius no preferien les plantes del desert als seus jardins, ans al contrari (St. Hilaire et al., 2003).

Els valors ambientals dels residents també influeixen en el tipus de jardineria que s'acaba practicant, ja que hi ha una forta relació positiva entre el nivell de conscienciació ambiental i el compromís de practicar una jardineria més ecològica (més estalviadora d'aigua, entre altres característiques) (Kiesling i Manning, 2010). Yabiku et al. (2008) van demostrar com unes fermes actituds i creences mediambientals (indicat a través de l'escala del «nou paradigma ecològic» [Dunlap et al., 2000]) portaven a rebutjar significativament l'opció del jardí mèsic. Larson et al. (2010) van trobar que les persones amb jardins tipus «oasi» eren, pel que feia a l'orientació dels seus valors, clarament antropocèntriques en comparació amb aquelles amb jardins totalment mèsics o xèrics. Contràriament al que s'esperava, una orientació clarament biocèntrica conduïa a triar un tipus de jardí en què dominava la gespa.

\subsection{Sistemes de reg i fonts de proveïment utilitzats}

En un estudi realitzat a Austràlia, es va poder comprovar que les llars amb els sistemes de reg de la gespa més tecnificats utilitzaven més aigua que aquelles amb sistemes de reg manuals (Syme et al., 2004). Els investigadors suggereixen que el motiu d'això rau en la tendència a configurar els temporitzadors per períodes més llargs o amb una freqüència més elevada de reg. En el cas de la Regió Metropolitana de Barcelona, Domene et al. (2005) també van observar que aquelles llars que posseïen un sistema de reg per aspersió acostumaven a tenir un jardí amb més demanda hídrica a causa de la seva associació freqüent amb la presència de gespa. Aquest fet també ha estat confirmat en altres estudis realitzats als EUA per Chesnutt i McSpadden (1991), els quals van constatar que una llar de Los Angeles amb un sistema d'aspersió automàtica consumia, de mitjana, un $11,2 \%$ més que aquells habitatges que utilitzaven sistemes d'aspersió manuals o que regaven a mà, fet que suposa una contradicció sorprenent, perquè, majoritàriament, es promou i es defensa la instal.lació de sistemes 
de reg automàtics com a mesura per estalviar aigua. Wentz i Gober (2007) van trobar que, tot i que el percentatge de jardí mèsic era una variable significativa, els coeficients d'estalvi d'aigua eren menors del que es podia esperar. Els autors argumenten que la causa podria raure en la suposició errònia que els jardins xèrics estalvien aigua per se $\mathrm{i}$ també que els residents amb dissenys xèrics de jardí no ajusten els seus sistemes de reg automàtic en consonància amb els canvis en l'evapotranspiració del seu jardí (St. Hilaire et al., 2003).

Pel que fa a les fonts de proveïment d'aigua utilitzades al jardí (sobretot pous i sistemes d'aprofitament d'aigües pluvials), és novament a Austràlia on s'han portat a terme més estudis sobre el tema. Segons l'Australian Bureau of Statistics (2006), l'11\% de l'aigua que es consumia als jardins de les llars d'aquest país provenia de recursos propis (pous i tancs d'aigua pluvial). Loh i Coghlan (2003), en el cas de la ciutat de Perth (Austràlia), van comprovar que aquelles llars que posseïen un pou (un 32\% del total dels casos estudiats) utilitzaven menys aigua de xarxa a l'estiu que aquelles que no en tenien. Novament en el cas d'Austràlia, es va trobar que, de mitjana, el 17,2\% dels residents posseïen un tanc d'aigües pluvials (Australian Bureau of Statistics, 2006). Domènech i Saurí (2011), aplicant un model hidràulic portat a terme pel cas del municipi de Sant Cugat de Vallès (Barcelona), revelen que, a les cases unifamiliars, la capacitat del tanc més eficient per satisfer la demanda d'aigua de reg era la de $22 \mathrm{~m}^{3}$, i que aquest volum òptim permetria estalviar el $61,7 \%$ de la demanda de reg, equivalent a $42 \mathrm{~m}^{3} /$ any o 38,3 litres per persona i dia.

No hi ha gaires estudis que hagin centrat l'atenció sobre quines són les motivacions que porten les llars a adoptar una font alternativa d'aigua. Ward et al. (2008) van investigar, a partir de les dades recollides d'enquestes a habitatges del Regne Unit, diversos aspectes que motivaven a desenvolupar un sistema d'aprofitament d'aigües pluvials. Quant a «la percepció del risc», es va trobar que aquest factor no havia de considerar-se una barrera important, sempre que l'ús no fos personal de l'individu. És a dir, utilitzar l'aigua per al reg del jardí era percebut com menys arriscat que utilitzar la mateixa aigua per dutxar-se, cuinar o beure. Els autors també van establir que els costos i les tasques de manteniment que implica la tinença d'un sistema d'aprofitament d'aigües pluvials sol subestimar-se. El seu qüestionari també cercava identificar els factors més rellevants que motivaven l'adopció d'un sistema d'aprofitament d'aigües pluvials. Els resultats van mostrar que la disponibilitat d'ajudes o subvencions $i$, en segon terme, l'estalvi de diners en la factura de l'aigua, van ésser les respostes més freqüents. Per tant, es pot concloure que les respostes involucren directament les barreres i els incentius econòmics com a principals factors que cal considerar. De fet, Loh i Coghlan (2003) van comprovar que les llars amb més ingressos disposaven d'un pou de manera més freqüent que les llars amb menys ingressos.

Comparativament, en un estudi realitzat a la regió de Melbourne (Catchlove et al., 2010), es va trobar que les motivacions principals per instal.lar un tanc d'aigües pluvials a les cases van ésser: l'estalvi directe d'aigua, evitar les restriccions hídriques estivals per regar el jardí i estalviar diners en la factura de 
l'aigua. Baguma et al. (2010) també van tractar de determinar els factors que influïen en l'adopció dels sistemes d'aprofitament d'aigües pluvials a nivell de la llar com a mesura de mitigació per assegurar el subministrament hídric a zones rurals d'Uganda. La investigació va trobar que la provisió de subvencions era l'única variable que en determinava significativament la possessió. No obstant això, no es van trobar relacions estadísticament rellevants entre l'adopció de sistemes d'aprofitament d'aigües pluvials i les variables socioeconòmiques de les llars explorades, és a dir, edat, ocupació, nivell educatiu, mida de la llar o ingressos mitjans mensuals.

\section{Conclusions}

Els processos urbanístics esdevinguts darrerament a l'àmbit mediterrani comporten l'aparició de pautes de consum noves entre els usuaris de l'aigua a casa seva i, per tant, es plantegen reptes nous en relació amb la gestió que s'ha de donar a aquest recurs. Des d'una visió pluridisciplinària, aquest article ha abordat la interrelació existent entre els processos d'urbanització $i$ els patrons socials de consum d'aigua per a usos domèstics, en especial en àmbits urbans de baixa densitat, i centrant l'atenció en la pràctica de la jardineria i els usos d'aigua que porta associats.

La sola possibilitat de poder gaudir d'un espai a l'exterior dels habitatges ofereix l'opció de poder portar a terme un conjunt d'activitats recreatives que impliquen un consum directe d'aigua. Diferents estudis han situat en un primer pla els usos exteriors de la piscina o el reg del jardí com els dos elements principals que poden necessitar més volum d'aigua, però sense poder discernir clarament quin dels dos exerceix més pressió en els consums. Unes altres característiques físiques dels habitatges, com ara la data de construcció, el model de tinença o el model d'ocupació, tot i haver estat pràcticament omeses en la majoria de models de la demanda hídrica elaborats en el passat, mostren que són elements que caldria tenir presents a l'hora d'elaborar futures estimacions de la demanda d'aigua centrades en la planificació i l'assignació del recurs.

El jardí és un element que pot reflectir els valors del seu propietari (antropocèntric o biocèntric), la seva identitat (afany de socialització o conformitat en relació amb la norma social), un mitjà per connectar amb la natura, fomentar les relacions familiars i amb les amistats, etc. Per tant, la tinença i el tipus de jardí que acull una llar és condicionat per un conjunt de variables més centrades en les característiques sociodemogràfiques i culturals dels residents. Tanmateix, hi ha uns altres factors, com ara la disposició espacial dels habitatges i els barris, o el propi preu de l'aigua, que igualment han de ser tinguts en compte.

A més, l'adopció d'una font alternativa d'aigua per al reg del jardí o uns altres usos exteriors de l'habitatge (sistemes de recol-lecció d'aigua de pluja, pous, iniciatives de reutilització hídrica, etc.) repercutirà molt positivament en els resultats, en disminuir la dependència de l'aigua provinent de la xarxa. Respecte a això, sembla que el grau de disposició d'ajudes econòmiques per 
instal-lar-los i la voluntat d'estalviar aigua, sobretot per disminuir-ne el cost econòmic, han esdevingut factors impulsors de l'adopció d'una font alternativa.

Un dels reptes més rellevants per als gestors de l'aigua en l'àmbit urbà és pal.liar els efectes de la urbanització difusa en el metabolisme hídric d'aquests espais residencials. El coneixement sobre els hàbits de consum de la població $i$ els factors que influencien en aquests hàbits esdevé fonamental per planificar actuacions futures relacionades amb la gestió de la demanda, inclòs l'ús de recursos alternatius i les campanyes de conscienciació en casos de penúria hídrica. Les aportacions en aquesta línia poden facilitar l'adopció de polítiques adequades a les realitats sociodemogràfiques i territorials de cada indret.

\section{Referències bibliogràfiques}

ARbuÉS, F.; BARbERÁn, R. i VillanÚA, I. (2008). «Tamaño de los hogares y demanda de agua residencial: una aproximación empírica». III Congreso de AERNA. Palma de Mallorca.

Arbués, F.; García-Valiñas, M.A. i Martínez-Espiñeira, R. (2003). «Estimation of residential water demand: a state-of-the-art review». The Journal of Socio-Economics, 32, 81-102.

ASKEW, L.E. i MCGUIRK, P.M. (2004). «Watering the suburbs: distinction, conformity and the suburban garden». Australian Geographer, 35, 17-37.

Australian Bureau of Statistics (2004). Water Account Australia 2000-01 [en línia].<http://www.abs.gov.au/ausstats/abs@.nsf/ProductsbyReleaseDate/8C8D D6F104A627DDCA257233001CE4A8?OpenDocument> [Consulta: 15 maig 2010].

- (2006). Water Account Australia 2004-05 [en línia]. <http://www.abs.gov.au/ AUSSTATS/abs@.nsf/DetailsPage/4610.02004-05> [Consulta: 30 juny 2010].

BAGUMA, D. i LOISKANDL, W. (2010). «Rainwater harvesting technologies and practises in rural Uganda: a case study». Mitigation and Adaptation Strategies for Global Change, 15, 355-369.

BAKIR, H. (2001). Water demand management and pollution control: Keys to securing and safeguarding the water supplies of the Eastern Mediterranean Region in the 21st century [en línia]. Amman: WHO Regional Centre for Environmental Health Activities. <http://www.emro.who.int/ceha/pdf/proceeding\%2001-water $\% 20$ demand\%20management1.pdf> [Consulta: 25 agost 2010].

BARKATULLAH, N. (1996). OLS and instrumental variable price elasticity estimates for water in mixed-effects model under multiple tariff structure. Report $n^{\circ} 226$. Sydney: Department of Economics. University of Sydney.

BhatTI, M. i ANDREW, C. (2004). «Home, the culture of nature and meanings of gardens in late modernity». Housing Studies, 19, 37-51.

BHATTI, M. i CHURCH, A. (2000). «I never promised you a rose garden: gender, leisure and home-making». Leisure Studies, 19, 183-197.

CATChlove, R.; MilenKOVIC, K.; RosSKaresh, S. i Brown, H. (2010). «Raingardens or rainwater tanks communityswillingness to install and effectiveness in achieving regional change». National Conference of the Stormwater Industry Association. Sydney.

Chestnutt, T. i McSpadden, C. (1991). A model-based evaluation of Westchester water conservation program. San Diego: A\&N Technical Services. 
Chicoine, D. i Ramamurthy, G. (1986). «Evidence on the specification of price in the study of domestic water demand». Land Economics, 62, 26-32.

Clarke, G.; Kashti, A.; MCDonald, A. i Williamson, P. (1997). «Estimating small area demand for water: a new methodology». CIWEM's Water and Environment Journal, 11, 186-192.

COlOM, M.C. i MolÉS, M.C. (1999). «Una aproximación a los condicionantes de la elección de vivienda secundaria». Estudios de Economía Aplicada, 11, 23-40.

DAndy, G.; NGUYEN, T. i DAVIES, C. (1997). «Estimating residential water demand in the presence of free allowances». Land Economics, 73, 125-139.

Davidson, D. J. i FreudenburG, W.R. (1996). "Gender and environmental risk concerns». Environment and Behavior, 28, 302-339.

Domene, E. i SAurí, D. (2003). «Modelos urbanos y consumo de agua: El riego de jardines privados en la Región Metropolitana de Barcelona». Investigaciones Geográficas, 32, 5-17.

- (2006). «Urbanisation and water consumption: Influencing factors in the Metropolitan Region of Barcelona». Urban Studies, 43, 1605-1623.

Domene, E.; SAURí, D. i PARÉS, M. (2005). «Urbanization and sustainable resource use: The case of garden watering in the Metropolitan Region of Barcelona». Urban Geography, 26, 520-533.

DOMĖNECH, L. i SAURí, D. (2011). "A comparative appraisal of the use of rainwater harvesting in single and multifamily buildings of the Metropolitan Area of Barcelona (Spain): Social experience, drinking water savings and economic costs». Journal of Cleaner Production, 19, 598-608.

Dunlap, R.; Van Liere, K.; Mertig, A. i Jones, R. (2000). «New trends in measuring endorsement of the new ecological paradigm: A revised NEP scale». Journal of Social Issues, 56, 425-442.

EUROPEAN ENVIRONMENT AGENCY (2006). Urban sprawl in Europe: The ignored challenge. Report Number 10/2006 [en línia]. Copenhagen: EEA. <http://www.eea. europa.eu/publications/eea_report_2006_10> [Consulta: 10 setembre 2009].

- (2009). Water resources across Europe-confronting water scarcity and drought: EEA Report 2/2009 [en línia]. Copenhagen: EEA. <http://www.eea.europa.eu/publications/water-resources-across-europe> [Consulta: 25 agost 2010].

Fox, C.; MCInTOSH, B.S. i JefFrey, P. (2009). «Classifying households for water demand forecasting using physical property characteristics». Land Use Policy, 26, 558-568.

GARDENER, G.T. i STERn, P.C. (1996). Environmental problems and human behavior. Boston: Allyn and Bacon.

GÖSSLING, S. (2002). "Global environmental consequences of tourism». Global Environmental Change, 12, 283-302.

HeAd, L.; Muir, P. i Hampel, E. (2004). «Australian backyard gardens and the journey of migration». Geographical Review, 94, 326-347.

HÖGLUND, L. (1999). «Household demand for water in Sweden with implications of a potential tax on water use». Water Resources Research, 35, 3853-3863.

Hope, D.; Gries, C.; Zhu, W.; Fagan, W.; Redman, C.L.; Grimm, N.B. i MarTIN, C. (2003). «Socioeconomics drive urban plant diversity». Proceedings of the National Academy of Science, 100, 8788-8792.

HurD, B.H. (2006). "Water conservation and residential landscapes: household preferences, household choices». Journal of Agricultural and Resource Economics, 31, 173-192. 
KiEsLing, F.M. i MANNING, C.M (2010). «How green is your thumb? Environmental gardening identity and ecological gardening practices». Journal of Environmental Psychology, 30, 315-327.

LARSEN, L. i HARLAN, S.L. (2006). «Desert dreamscapes: Residential landscape preference and behavior». Landscape and Urban Planning, 78, 85-100.

Larson, K.L.; Casagrande, D.; Harlan, S.L. i YabikU, S.T. (2009). «Residents' yard choices and rationales in a desert city: Social priorities, ecological impacts, and decision tradeoffs». Environmental Management, 44, 921-937.

Larson, K.; COOK, E.; STRAWHACKer, C. i Hall, S. (2010). "The Influence of Diverse Values, Ecological Structure, and Geographic Context on Residents' Multifaceted Landscaping Decisions». Human Ecology, 38, 747-761.

Loh, M. i Coghlan, P. (2003) Domestic water use study: Perth, Western Australia 1998-2001 [en línia]. Perth: Water Corporation. <http://watercorporation.com. au/_files/PublicationsRegister/12/Domestic_water_use_study.pd> [Consulta: 15 novembre 2009].

Martínez-EspiñeIRA, R. (2002). "Residential water demand in the Northwest of Spain». Environmental and Resource Economics, 21, 161-187.

Mayer, P.W.; DeOreo, W.B.; Opitz, E.; Kiefer, J.; Dziegielewski, B.; Davis, W.; DzIEGIElewsKi, B. i Nelson, J.O. (1999). Residential end uses of water. Denver: American Water Works Association Research Foundation.

MÓdEnES, J.A. i COLÁs, J.L. (2005). «Expansión territorial de la residencia secundaria y ciudad compacta en España: ¿Elementos de un mismo sistema?». Comunicació presentada a la XXV Conferència Internacional de Població, IUSSP. Cesio 168: "Circulació $i$ suburbanització». Tours.

Molés, M. i Colom, M. (2006). «Un modelo de elección del régimen de tenencia y tipo de vivienda en España: Una comparación entre el ámbito urbano y el ámbito rural». Estudios de Economía Aplicada, 24-2, 657-676.

Mustafa, D.; Smucker, T.A.; Ginn, F.; Johns, R. i Connely, S. (2010). «Xeriscape people and the cultural politics of turfgrass transformation». Environment and Planning D, 28, 600-617.

Nauges, C. i Thomas, A. (2000). «Privately-operated water utilities, municipal price negotiation, and estimation of residential water demand: The case of France». Land Economics, 76, 68-85.

NieswiAdOMY, M. i CoBb, S. (1993). «Impact of pricing structure selectivity on urban water demand». Contemporary Policy Issues, 11, 101-113.

Nieswiadomy, M. i Molina, D. (1989). «Comparing residential water demand estimates under decreasing and increasing block rates using household data». Land Economics, 65, 280-289.

ORGANITZACIÓ DE LES NACIONS UNIDES (2006). International decade for action. Water for life, 2005-2015. Factsheet on water and sanitation [en línia]. <http://www. un.org/waterforlifedecade/factsheet.html> [Consulta: 1 agost 2009].

PINT, E.A. (1999). «Household responses to increased water rates during the California drought». Land Economics, 71, 173-92.

RENWICK, M. i ARCHibald, S. (1998). «Demand side management policies for residential water use: who bears the conservation burden?». Land Economics, 74, 343-359.

Rico-Amorós, A.M.; Olcina-Cantos, J. i Sauri, D. (2009). «Tourist land use patterns and water demand: Evidence from the Western Mediterranean». Land Use Policy, 26, 493-501. 
Rueda, S. (1995). Ecologia urbana, Barcelona i la seva Regió Metropolitana com a referents. Barcelona: Beta Editorial.

SAurí, D. (2003). "Lights and shadows of urban water demand management: The case of the Metropolitan Region of Barcelona». European Planning Studies, 11, 229-243.

Sime, J. (1993). «What makes a house a home: the garden?». A: Bulos, M. i TeYMUR, N. (eds.). Housing: Design, research, education. Avebury: Aldershot, 239-254.

ST. Hilaire, R.; SpinTi, J.E.; VAn LeEuwen, D. i Smith, C. (2003). Landscape preferences and attitudes toward water conservation: A public opinion survey of homeowners in Las Cruces, New Mexico. New Mexico: New Mexico State University. Agricultural Experiment Station.

Syme, G.J.; Kantola, S.J. i Thomas, J.F. (1980). «Water resources and the quarter acre block». A: Thorne, R. i Arden, S. (eds.). People and the Man Made Environment. Sydney: University of Sydney, 192-201.

Syme, G.J.; Seligman, C. i Thomas, J.F. (1990-1991). «Predicting water consumption from homeowners' attitudes». Journal of Environmental Systems, 20, 157-168.

Syme, G. J.: ShaO, Q.; Po, M. i Campbell, E. (2004). «Predicting and understanding home garden water use». Landscape and Urban Planning, 68, 121-128.

Troy, P. (2005). «Saving our cities with suburbs». A: SCHULTZ, J. (ed.). Griffith Review: Dreams of Land. 2a ed. Sydney: ABC Books.

Troy, P. i Holloway, D. (2004). "The use of residential water consumption as an urban planning tool: a pilot study in Adelaide». Journal of Environmental Planning and Management, 47, 97-114.

WARD, S.; Butler, D. i MEMON, F.A. (2008). "A pilot study into attitudes towards and perceptions of rainwater harvesting in the UK». 10th British Hydrological Society National Hydrology Symposium. Exeter.

WENTZ, E. i GOBER, P. (2007). «Determinants of small-area water consumption for the city of Phoenix, Arizona». Water Resources Management, 21, 1849-1863.

Yabiku, S.T.; Casagrande, D.G., i Farley-Metzger, E. (2008). «Preferences for landscape choice in a Southwestern desert city». Environment and Behavior, 40, 382-400.

YePES, G. i DiANDERAS, A. (1996). Water and wastewater utilities indicators [en línia]. 2a ed. Water and Sanitation Division. World Bank. <http://www.worldbank.org> [Consulta: 20 abril 2009].

ZMYSLONY, J. i GAGNON, D. (2000). «Path analysis of spatial predictors of front-yard landscape in an anthropogenic environment». Landscape Ecology, 15, 357-371. 